\title{
Caranguejo Uçá (Ucides cordatus Linnaeus 1763): gestão sustentável do caranguejo uçá na APA/ARIE da Foz do Rio Mamanguape
}

Letyssia Maynarth de Oliveira Soares ${ }^{1 *}$ (D), George Emmanuel Cavalcanti de Miranda ${ }^{2}$ (D), José da Silva Mourão ${ }^{3}$

\footnotetext{
${ }^{1}$ Mestrado em Desenvolvimento e Meio Ambiente, Universidade Federal da Paraíba - Campus I, Cidade Universitária, João Pessoa, PB, Brasil. 58051-901

${ }^{2}$ Departamento de Sistemática e Ecologia, Centro de Ciências Exatas e da Natureza, Universidade Federal da Paraíba Campus I, Cidade Universitária, João Pessoa, PB, Brasil. 58051-901

${ }^{3}$ Departamento de Biologia, Centro de Ciências Biológicas e da Saúde, Universidade Estadual da Paraíba, Campus Universitário do Bodocongó, R. Aprígio Veloso, 882, Campina Grande, PB. 58429-500

* Autor para correspondência: letyssiasoares@hotmail.com
}

Recebido em 13 de março de 2020.

Aceito em 03 de setembro de 2020.

Publicado em 30 de setembro de 2020.

Resumo - A eficiência das unidades de conservação (UC) acha-se no tipo de governança praticada e no estabelecimento dos instrumentos de gestão ambiental. A gestão das UC no Brasil preconiza um modelo participativo e compartilhado, contudo, seu exercício é um desafio para os órgãos ambientais. Assim, a presente estudo teve por objetivo avaliar as contribuições e participação dos catadores de caranguejo na gestão e manejo sustentável do caranguejo uçá (Ucides cordatus) na APA/ARIE da Foz do Rio Mamanguape, bem como a percepção deles sobre ao modelo de gestão. A metodologia se apoia na percepção e no conhecimento ecológico local, tratando-se de uma pesquisa quali quantitativa, com o uso das técnicas observação participante e entrevista semiestruturada. $\mathrm{O}$ estudo expõe a cadeia produtiva do caranguejo Uça na APA/ARIE da Foz do Rio Mamanguape e a participação do caranguejeiro no processo de gestão. Verificou-se que o manejo do Caranguejo-uçá praticada pelos catadores é feito dissociado da governança das unidades de conservação e que existe um distanciamento entre caranguejeiro, conselho gestor e ICMBIO. Dessa forma conclui-se que a gestão do recurso caranguejo uçá é do tipo centralizada e a política que norteia o manejo do recurso não atende os aspectos locais.

Palavras-chave: Unidade de conservação. Conhecimento Ecológico local. Gestão ambiental.

\section{Uçá crab (Ucides cordatus Linnaeus 1763): sustainable management of the Uçá crab in the APA / ARIE of Foz do Rio Mamanguape}

Abstract - The efficiency of Protected Areas (PA) is found in the type of governance practiced and in the establishment of environmental management instruments. The management of PA in Brazil advocates a participatory and shared model, however, its exercise is a challenge for environmental agencies. Thus, this study aimed to assess the contributions and participation of crab catchers in the management and sustainable management of the Uçá crab (Ucides cordatus) at the APA / ARIE of Foz do Rio Mamanguape, as well as their perception of the management model. The methodology is based on the perception and local ecological knowledge, being a qualitative quantitative research, 
using the techniques of participant observation and semi-structured interview. The study exposes the Uçá crab production chain at the APA / ARIE of Foz do Rio Mamanguape and the participation of the crab catchers in the management process. One of the findings is that the management of the Uçá crab practiced by the catchers is dissociated from the governance of the conservation units and that there is a gap between the crab catchers, management council and ICMBIO. Thus, it is concluded that the management of the Uçá crab resource is centralized and the policy guiding the management of this resource does not meet the local aspects.

Key words: Conservation unit. Local Ecological Knowledge. Environmental management.

\section{Cangrejo Uca (Ucides cordatus Linnaeus 1763): gestión sostenible del cangrejo uca en la APA / ARIE de la Foz do Rio Mamanguape}

Resumen - La eficiencia de las unidades de conservación (UC) se encuentra en el tipo de gobernanza que se practica y en el establecimiento de instrumentos de gestión ambiental. La gestión de la UC en Brasil recomienda un modelo participativo y compartido, sin embargo, su ejercicio es un desafío para las agencias ambientales. Así, el presente estudio tuvo como objetivo evaluar las contribuciones y participación de los recolectores de cangrejos en la gestión y manejo sustentable del cangrejo Uca (Ucides cordatus) en la APA / ARIE de la Foz do Rio Mamanguape, así como su percepción del modelo de gestión. La metodología se basa en la percepción y el conocimiento ecológico local, siendo una investigación cualitativa y cuantitativa, utilizando las técnicas de observación participante y entrevista semiestructurada. El estudio expone la cadena de producción de cangrejo Uca en la APA / ARIE de la Foz do Rio Mamanguape y la participación del recolector de cangrejos en el proceso de gestión. Se encontró que el manejo del Caranguejo Uca practicado por los recolectores está disociado de la gobernanza de las unidades de conservación y que existe una distancia entre el cangrejo, el consejo de gestión y el ICMBIO. Así, se concluye que la gestión del recurso cangrejo uca es de tipo centralizado y la política que guía el manejo del recurso no responde a los aspectos locales.

Palabras clave: Unidad de conservación. Conocimiento Ecológico local. Gestión ambiental.

\section{Introdução}

As unidades de conservação (UC) dentro da categoria de uso sustentável são relevantes instrumentos de proteção dos recursos ambientais e do modo de vida tradicional. Países da Europa e da América do Norte que possuem áreas protegidas, cuja governança ambiental se respalda na proteção e no uso sustentável dos recursos ambientais, vivenciam experiências exitosas na recuperação e manutenção do meio ambiente, como demonstram os estudos de Driessen et al. (2012), Fenberg et al. (2012) e Sandstrom et al. (2015). Contudo, no Brasil a realidade mostra-se diferente, uma vez que, mesmo com a criação das UC, o modelo de governança ambiental praticado pelos órgãos ambientais dificulta o gerenciamento dos recursos ambientais (Jentoft 2015).

De acordo com o Sistema Nacional de Unidades de conservação - SNUC, Lei 9985/00, o modelo de governança ambiental utilizado para gerir as UC é do tipo participativo e compartilhado, mediante a criação de um conselho gestor. No entanto, quando a produtividade dos conselhos é analisada, percebe-se que suas ações ocorrem em circunstâncias pontuais, baseadas nas regulações diretas (leis federais, estaduais e municipais) e/ou na regulação indireta, tais como: o Plano de Manejo, acordos de gestão e uso. 
O ato de estabelecer as regulações indiretas para uma unidade de conservação permite aprimorar as regulações diretas e adaptá-las à realidade local. Essa ação, propicia o exercício da democracia, eleva o capital social dos grupos e estimula a estruturação e implementação de políticas de qualidade e de adaptabilidade dinâmica, por dar maior abertura para os usuários dos recursos ambientais nos espaços coletivos (Linares et al. 2009).

As políticas ambientais contemporâneas estimulam o engajamento e a participação dos representantes do poder público e da sociedade civil na sua construção, fazendo com que esse processo participativo e de compartilhamento de poder, coopere com o sucesso da implementação de uma gestão ambiental voltada à proteção da biodiversidade e ao gerenciamento sustentável dos recursos ambientais, em destaque os pesqueiros (Kalikoski 2009; Micheli et al. 2013; Sandström et al. 2015).

Incorporar os usuários dos recursos costeiros, principalmente aqueles que fazem uso dos recursos ditos de "uso comum" e seu conhecimento ecológico local - CEL - na gestão do meio ambiente e na elaboração dos acordos de pesca, estimula o desenvolvimento do conhecimento útil dos usuários e o sentimento de pertencimento, resultando no maior envolvimento dos atores social nos processos de tomadas de decisão e/ou na resolução de conflitos (Gerhardinger et al. 2009).

Assim, o presente artigo tem como foco a gestão e manejo do caranguejo uçá (Ucides cordatus) na Área de Proteção Ambiental (APA) da Barra do Rio Mamanguape e na Área de Relevante Interesse Ecológico (ARIE) de Manguezais da Foz do Rio Mamanguape. Nessa região, o caranguejo uçá representa uma das principais fontes de renda para a população local e o recurso mais explorados da região (Rocha et al. 2008).

O referido estudo teve por objetivo avaliar as contribuições e participação dos catadores de caranguejo na gestão e manejo do caranguejo uçá (Ucides cordatus) na APA/ARIE da Foz do Rio Mamanguape. O desenvolvimento deste trabalho se justificada pela necessidade de perceber a gestão do recurso caranguejo e das unidades de conservação do ponto de vista do catador de caranguejo. Os resultados encontrados propiciarão aos gestores das UC's uma avaliação das ações que norteiam o recurso caranguejo e a relação do referido recurso na vida de seus usuários. Contribuirá também na proposição de diretrizes e ações que compatibilize, integre e otimize a interação da gestão com a população tradicional, indicando mecanismos para a realização de uma gestão compartilhada de maneira plena.

\section{Material e métodos}

\section{Área de estudo}

A presente pesquisa foi realizada na Área de Preservação Ambiental (APA) da Barra do Rio Mamanguape e na Área de Relevante Interesse Ecológico (ARIE) Manguezais da Foz do Rio Mamanguape, nas comunidades de Tramatáia, Camurupim, Três Rios, Tavares, Tanques e Taberaba, povoados localizados às margens do estuário do Rio Mamanguape e que pertencem aos municípios de Marcação e Rio Tinto no Estado da Paraíba, nordeste do Brasil.

A APA da Barra do Rio Mamanguape foi criada em de 10 de setembro de 1993, através do Decreto Federal no 924. Distante $70 \mathrm{Km}$ da capital João Pessoa, a citada UC está localizada entre os municípios de Rio Tinto, Lucena, Marcação e Baia da Traição, e detém uma extensão territorial de 14.640 hectares, que abrange o território continental, estuarino e marinho. 
A ARIE Manguezais da Foz do Rio Mamanguape teve sua criação em 05 de novembro de 1985, por meio do decreto $\mathrm{n}^{\circ}$ 91.890. Detentora de uma área de 5.721,07 hectares, a ARIE está localizada no interior da APA da Barra do Rio Mamanguape, na porção pertencente ao município de Rio Tinto/ $\mathrm{PB}$, se detendo apenas as áreas de mangue e estuário.

A paisagem natural da região é formada por ecossistemas do bioma costeiros e marinhos, tais como manguezais, restinga, dunas, estuário, recifes e falésias e remanescentes de mata atlântica (Rocha et al. 2008; Ferreira et al. 2009; Nascimento et al. 2012). Referente aos comunitários da região, destaca-se que estes possuem descendência africana, europeia e indígena Potiguara e que eles têm estreita relação de dependência com os manguezais, tanto do ponto de vista da sobrevivência, quanto da manutenção cultural (Paludo e Klonowski 1999).

Embora as áreas de manguezais situados nas UC sejam visivelmente bem conservadas, esse ambiente sofre com as pressões das atividades humanas, sobretudo aquelas do tipo diretas, que estão relacionadas à exploração dos recursos estuarinos. No tocante às pressões indiretas, destacam-se na região as atividades da indústria sucroalcooleira, a carcinicultura, agricultura familiar, expansão urbana desordenada e escassez de oferta de emprego formal (Silvestre 2011).

O estudo de Rocha et al. (2008), evidencia que os recursos estuarinos mais explorados na região são espécies de peixes, crustáceos e moluscos. Em relação aos crustáceos, as espécies com maior relevância economia são a lagosta vermelha, o caranguejo uçá e o guaiamum (Alves e Nishida 2005; Rocha et al. 2008). Destaca-se que na região a captura do caranguejo uçá é a atividade mais realizada, cujo impacto é observado diretamente na redução do estoque do recurso nos manguezais (Nascimento 2012).

\section{Coleta de dados}

O trabalho foi desenvolvido a partir do uso de métodos e técnicas de pesquisa social, tais como, observação participante e entrevista semiestruturada. Para compreender melhor o sujeito da pesquisa, optou-se pela realização de visitas técnicas e acompanhamento das atividades organizadas pelo Instituto Chico Mendes de Conservação da Biodiversidade (ICMBIO) voltadas para a promoção da proteção e conservação do caranguejo uçá (Ucides cordatus).

As visitas técnicas ocorreram ao longo do ano de 2016 para possibilitar o reconhecimento da área de estudo, estabelecer vínculos de confiança com os comunitários e compreender a realidade socioambiental da região. No que toca o acompanhamento das ações do ICMBIO, optou-se por participar das reuniões do conselho gestor das UC e das oficinas para atualização do marco regulatório do caranguejo uçá, Portaria IBAMA no 34/03-N de 24 de junho de 2003.

A aplicação das entrevistas e o exercício da observação participante iniciaram no segundo semestre de 2017 e mostraram-se ferramentas eficientes no levantamento de informações. Salientamos que o uso em conjunto dos métodos contribuiu para que questões não apresentadas nas entrevistas fossem externalizadas na observação participantes e vice-versa.

As entrevistas e observação participante ocorreram nos mais variados ambientes, no rio, no mangue, e/ou nas residências. As entrevistas foram realizadas individual ou coletivamente, com ou sem o uso de gravador. Quando o uso do gravador não era concedido e/ou não era possível seu uso, as informações mais importantes foram anotadas em diário de campo. 
O espaço amostral foi composto por 43 catadores de caranguejo, respeitando o seguinte perfil: idade entre 30-60 anos; 10 anos de profissão como caranguejeiro; coleta caranguejo pelo menos 3 vezes por semana; e renda familiar baseada na venda do caranguejo uçá, com ou sem ajuda de algum programa social.

Para Verso e Pedro (2012), a entrevista é uma técnica voltada para a produção e significação da memória. O uso desse método contribuiu com o levantamento do conhecimento útil e do conhecimento ecológico local dos caranguejeiros sobre a criação das UC e seus impactos positivos ou negativos na condição socioambiental da região.

Todas as entrevistas foram transcritas, respeitando a oralidade do sujeito da pesquisa. Visando garantir o anonimato dos entrevistados, optou-se pelo uso de nomes de pássaros como pseudônimos, em razão da peculiar maneira de comunicação utilizada pelos caranguejeiros no mangue, o assobio.

Em razão dos aspectos éticos e legais, o projeto de pesquisa que deu origem a este artigo, foi cadastrado e aprovado no Sistema de Autorização e Informação em Biodiversidade (SISBIO) através do código 63572337 e no Comitê de ética em pesquisa (CEP) da Universidade Federal da Paraíba (UFPB), pelo parecer no 2.357.719.

\section{Resultados e discussão}

\section{Cadeia produtiva do caranguejo uçá no estuário do Rio Mamanguape}

A cadeia produtiva do caranguejo-uçá no estuário do Rio Mamanguape tem seu início nas residências dos caranguejeiros, quando estes confeccionam seus petrechos de pesca (redinha), antes de ir ao manguezal e tem seu fim na venda do caranguejo e/ou do seu subproduto (carne de caranguejo e patola).

Embora a portaria do IBAMA no 34/2003 determine o método de braceamento, com ou sem o auxílio de gancho para a captura do caranguejo uçá, na região estudada a "redinha" é a técnica utilizada. A técnica da "redinha" consiste em uma armadilha confeccionada com sacolas de polipropileno desfiada e amarradas nas extremidades junto a saída das "locas" dos caranguejos.

A redinhafoiadotada pelos caranguejeiros do estuário do Rio Mamanguapea aproximadamente 20 anos, no entanto, nenhum entrevistado sabe dizer ao certo quem introduziu a técnica na região. A incorporação dessa nova tecnologia, cooperou para o abandono do modo tradicional de captura do caranguejo, o tapamento e braceamento.

A ruptura com a técnica tradicional de captura do caranguejo uçá observada por Alves e Nishida (2003) e Nascimento et al. (2012), reflete uma transição cultural vivenciada nas comunidades inseridas na APA. A supressão do tapamento nas comunidades é resultado da desvalorização da técnica e de seu esquecimento, posto que, o modo tradicional de catar o caranguejo não está sendo repassada para a nova geração de caranguejeiros, ficando apenas na memória dos mais velhos.

O uso em massa da redinha reflete a praticidade da técnica, que torna a captura do caranguejouçá mais rápida e menos desgastante para o catador. Nascimento et al. (2016), afirmam que a substituição da técnica tradicional pela redinha também está atrelada a baixa produtividade no uso de outras técnicas e a retorno financeiro da espécie. Somada a natureza predatório do uso da redinha, foi identifica a poluição física que a mesma causa ao ambiente, uma vez que é facilmente visualizado enlaçados a vegetação ou flutuando no estuário fragmentos de redinhas. 
Apesar de 76\% dos caranguejeiros entrevistados terem consciência do conjunto de problemas gerados pelo uso da redinha, $98 \%$ dos relatos demonstram que o uso da "nova" técnica é mais seguro para os catadores, visto que no tapamento, o caranguejo é "arrancado" com o auxílio do braço, deixando-os vulneráveis à acidentes, como cortes nos braço, antebraço e mão, assim como, a picadas e mordidas de outras espécies da fauna local.

Nascimento et al. (2011) externalizam a dicotomia que existe na incorporação de novas técnicas, que por um lado intensifica a captura do recurso, mostrando-se algo positivo para os caranguejeiros, mas por outro, estabelece uma relação predatória de uso do recurso, que ameaça o estoque do caranguejo e a sobrevivência do grupo de pessoas que dependem do mesmo.

Quando questionados sobre a sustentabilidade da redinha, 78\% dos catadores entrevistados consideram que a técnica não é predatória, no entanto, 96\% remetem à escassez do recurso a maneira como muitos caranguejeiros atuam na captura do caranguejo uçá, quando armam um número elevado de redinhas e não conseguem retirá-las. O estudo de Nascimento et al. (2012) demonstrarou que o uso da redinha causa impactos significativos ao estoque de caranguejo e ao ecossistema manguezais, embora não tenha encontrado dados quantitativos que comprovam o caráter predatório da técnica.

Baseado no apresentado pelo autor citado anteriormente, entende-se que é desejável a realização do estudo populacional da espécie e o conhecimento ecológico local - CEL - dos catadores de caranguejo, para avaliar sustentabilidade do uso da redinha e definir limites e normas de uso. O referido estudo embasaria a atualização da portaria do IBAMA n³4/2003 e a formulação de acordos de pesca direcionado ao uso do recurso na região. Machado et al. (2011) afirmam que a sustentabilidade do uso dos recursos de uso comum apenas será alcançada a partir do manejo adaptativo, ou seja, pela elaboração de políticas ambientais adaptadas à realidade local e que respeitam as mudanças sociais.

Uma condição singular no exercício do manejo sustentável do caranguejo uçá e do mangue é a presença dos caranguejeiros "especialistas", que correspondem a $23 \%$ dos entrevistados. Esses catadores de caranguejo tiveram suas vidas de mangue iniciada logo quando crianças, em meio às fábulas e seres míticos, a exemplo do "Pai do Mangue". Hoje com idades acima de 50 anos, eles têm elevado conhecimento ecológico local sobre a atividade e uma forte relação de respeito com o ambiente.

Verificou-se também que os catadores de caranguejo especialistas vivenciaram um período de grande mortandade de caranguejo-uçá no estuário. Entre os anos de 1998/1999 foi um momento triste e difícil nas vidas deles, já que muitos viviam exclusivamente do mangue. Dessa forma, inferese que a valorização do mangue e do caranguejo e a maior consciência ambiental por parte desse grupo, está associada às dificuldades vividas por eles nesse período.

\footnotetext{
“Teve uma época que aqui o caranguejo morreu todinho e não tinha como a pessoa sobrevivê. Muita gente aqui passô necessidade. Aí eu não sei, deve tê sido coisa de Deus mermo, que deu uma cheia e colocô esse caranguejo todinho de novo no mangue." (Garça-caranguejeira)
}

Nesse estudo foi visto que $100 \%$ dos caranguejeiros consideram que a margem direita do estuário do Rio Mamanguape é a área mais utilizada na cata do caranguejo, dado que, o mangue se encontra mais bem preservada e há maior disponibilidade de recurso. Para 92\% a baixa disponibilidade de caranguejo na margem esquerda do estuário do rio Mamanguape está relacionada aos viveiros de camarão construídos em áreas de mangue; ao crescimento desordenado das comunidades; a sobre- 
exploração do caranguejo na região; ao elevado número de caranguejeiros da região, em razão do desemprego e; a dificuldade em aplicar a lei em terras indígenas.

Os caranguejeiros definem a seleção da área do mangue onde será realizada a catação do caranguejo com base em dois critérios principais: regiões que não tenham sido trabalhadas no dia anterior e que não estejam sendo exploradas naquele instante. O exercício do rodízio nos ambientes do mangue é praticado por $100 \%$ dos entrevistados e deve ser visto como um momento de recuperação do mangue, que permite que os caranguejos pequenos cresçam e que outros venham habitar aquele espaço.

Os catadores de caranguejo costumam compartilhar informações sobre a qualidade do mangue e do caranguejo, sinalizando as áreas que sofrem superexploração do recurso e precisam se reestabelecer, entretanto, $73 \%$ dos entrevistados afirmam que estas áreas seguem sendo exploradas por catadores caranguejeiros que não tenham "consciência" e que em sua maioria são catadores "jovens".

A superexploração do caranguejo-uçá relatada pelos caranguejeiros, além de estar associada à coleta predatória, também é explicada pelo o número de indivíduos que adentraram na atividade do caranguejo em razão do desemprego, ou na busca de uma renda extra. Nesse ponto, a redução do estoque de caranguejo se encontra imerso nos seguintes dilemas: A "tragédia dos comuns" nos moldes como apresentada por Garret Hardin em 1968; a falta de capacidade e limitação dos órgãos ambientais em regulamentar o uso deste recurso e; a falta de participação comunitária na gestão direta do recurso, ideia alternativa à gestão centralizada, como defendida por Ostrom (1990).

Um dos principais problemas relacionados ao uso da técnica da "redinha" está relacionado à permanência das mesmas no mangue por mais de um dia. Neste aspecto, $24 \%$ dos entrevistados não consideram o ato de deixar redinha no mangue um problema, desde que no dia seguinte o caranguejeiro tenha o compromisso de remover todas as armadinhas do mangue, solte os caranguejos capturados menores que $6 \mathrm{~cm}$ e as fêmeas, assim como qualquer outro animal que esteja preso à redinha. Para os 76\% (ampla maioria dos entrevistados), não se deve deixar redinhas armadas no mangue sobre nenhuma condição.

A grande maioria dos caranguejeiros (87\%) destacam em suas falas as práticas que tornam o uso da redinha sustentável. Todavia, tais argumentos não são considerados e/ou de conhecimento do órgão gestor (ICMBio). Desse modo, sugere-se que a gestão governamental considere a possibilidade de criar um acordo de pesca voltado para a cata do caranguejo com o uso da redinha, que sejam ouvidos os catadores, principalmente pelo fato de que a técnica estabelecida em lei (braceamento), não é mais praticada na região pela totalidade dos entrevistados.

Ruddle e Davis (2013) afirmam que a colaboração entre população local e cientistas estimula o empoderamento local, a valorização das experiências e dos aspectos locais. Tal circunstância, provoca uma expressiva participação e a sobreposição dos saberes da comunidade sobre a academia e instituição ambiental. O mesmo autor conclui que o contato entre sociedade civil, instituições de ensino superior e poder público, aumentam o intercambio e apropriação de conhecimentos, assim como, colaboram no registro da percepção da comunidade.

Para 52\% dos catador de caranguejo entrevistos, alcançar o manejo sustentável do caranguejo a partir do uso da redinha é possível a partir do exercício das seguintes ações: o caranguejeiro colocará até 200 redinhas por dia; levará para casa apenas caranguejos do sexo masculino e com tamanho adequado para a venda; a coleta de fêmeas será permitida apenas para consumo próprio; independente da forma da venda do recursos, o mesmo deverá ser melhor valorado; as redinhas armadas que não 
forem malhadas deverão ser removidas e levadas para casa, exceto se o caranguejeiro for trabalhar no dia seguinte no mesmo mangue; priorizar a reutilização das gaitas (pedaços de raízes utilizadas para fixar a redinha); retirar o caranguejo da redinha em casa, para não deixar resíduo no mangue; ter seguro de três meses no período da andada, o caranguejeiro não irá ao mangue nos meses de vigência do seguro e será o fiscal do mangue nesse período.

Os dados de produção estimados a partir das entrevistas mostram que a quantidade de recurso extraído semanalmente por catador de caranguejo é de aproximadamente 60 cordas numa maré boa e de 30 cordas numa maré ruim. Uma corda de caranguejo, na região, é composta por 12 caranguejos e seu preço oscila entre $\mathrm{R} \$ 5,00$ e $\mathrm{R} \$ 10,00$.

A flutuação do preço da corda do caranguejo está intrinsecamente relacionada à qualidade do caranguejo, à forma como o recurso é vendido e à maneira como a cata do caranguejo é realizada. O caranguejo vendido pelo caranguejeiro profissional é um recurso selecionado, que atendem aos parâmetros que preconiza a lei (livre de fêmeas e com tamanho igual ou maior que $6 \mathrm{~cm}$ ). Esse recurso é vendido principalmente em feiras e o valor da corda varia entre $R \$ 7,00$ e $R \$ 10,00$. O recurso repassado para atravessadores tem tamanhos variados, cada corda contém no máximo duas fêmeas e o seu valor é de $\mathrm{R} \$ 5,00$.

O beneficiamento do caranguejo tem seu processo dividido em quatro etapas: cozimento; desmembramento; lavagem e extração da carne (Nascimento et al. 2017). A atividade realizada pelos atravessadores (fora do núcleo familiar dos caranguejeiros) se restringe à produção da carne do caranguejo, que é feita com o auxílio de um compressor ou manualmente, não se tratando de uma atividade exclusivamente feminina. Conforme os autores citados anteriormente, a etapa final da extração pode ser realizada por um terceiro grupo, normalmente formada por mulheres, que recebem o recurso cozido e desmembrado para ser realizada apenas a extração. O valor pago é de $\mathrm{R} \$$ 4,00 a $\mathrm{R} \$ 5,00$ por quilo de carne extraído.

Caranguejeiros entrevistados informaram que o caranguejo beneficiado por atravessadores normalmente tem tamanho menor que $6 \mathrm{~cm}$ e são de ambos os sexos. Ainda, esses caranguejeiros afirmam que as pessoas que extraem esses recursos não são caranguejeiros profissionais, mas sim, pessoas que trabalham nas usinas de cana-de-açúcar e que vão ao mangue com o intuito de complementar a renda familiar. Recorre-se a fala abaixo para fortalecer a afirmação, esta é uma situação grave que precisa regulamentação urgente.

"O atravessado é o mal do caranguejo e do mangue. Eles compra tudo, num qué sabê se é miúdo, ô se é fêmea [...]”. (Alma-de-gato)

Diferentemente dos atravessadores, o beneficiamento realizado no núcleo familiar dos caranguejeiros tem como subproduto a carne e a patola do caranguejo (musculatura da quela do caranguejo). Apesar de ser realizada por poucas famílias, o beneficiamento do caranguejo é uma atividade exclusivamente feminina, realizada pelas esposas e filha(s) do caranguejeiro. A extração dos subprodutos do caranguejo é realizada de forma manual e são feitas apenas sob encomenda. Em média o valor de $1 \mathrm{~kg}$ de carne de caranguejo é de $\mathrm{R} \$ 25,00$ e 24 unidades de patola custa $\mathrm{R} \$ 50,00$, demonstrando uma maior relevância na economia doméstica.

Quando criada uma linha temporal que tem seu início no período da criação da APA até a atualidade, observando a questão da qualidade do mangue, do caranguejo e do estuário, para 100\% dos entrevistados pouquíssimas mudanças ocorreram no estuário do Rio Mamanguape e destacam 
melhorias na qualidade do mangue. Dados históricos demonstram que a extração de madeiras de mangue era uma atividade forte na região e que tinha como destino construção de casas, uso como combustível doméstico e a produção de carvão (Paludo e Klonowski 1999).

A proibição do corte de madeira extinguiu a profissão de lenhador na região e contribuiu com a melhoria da condição do mangue, fato que só foi possível após a criação das UC. Outra intervenção importante na região foi fechamento de alguns viveiros de camarão, que foram construídos em área de mangue. No entanto, os relatos demonstram que o excesso de pessoas trabalhando no mangue tem impactado negativamente a vegetação, como será visto no discurso abaixo.

\footnotetext{
"O mangue era bem verdinho, o mangue era muito bonito. Hoje o mangue o mangue está muito estragado, porque é muita gente trabalhando [...].” (Papa-lagarta-do-mangue)

“[...] logo quando tinha aquele vivero de camarão, prejudicava muito. Mai aí ele fechô. Lá a gente fez uma plantação de mangue, rapaz, ô plantação bonita! mas também já estão destruindo já. Eu só vejo o mangue já cortado, tão entrando com tudo." (Tuim)
}

Não existem dados quantitativos que possibilitem uma avaliação da evolução temporal da população deste recurso, inclusive porque a mortandade do caranguejo-uçá ocorrida em 1998, fenômeno que ocorreu em vários estuários pelo Brasil, paralisou a atividade na região. No entanto, $48 \%$ dos caranguejeiros percebem que o caranguejo ao longo dos anos (pós-mortalidade) tem melhorado com relação à quantidade, mas, em razão do número de pessoas trabalhando no mangue, poucos são os caranguejos que alcançam o tamanho adequado para a venda.

Conforme os relatos de $71 \%$ dos catadores de caranguejo entrevistados, o estuário do Rio Mamanguape vem ao longo dos anos sofrendo um intenso processo de assoreamento, onde antes entravam embarcações relativamente grandes, hoje existem áreas do rio que os caranguejeiros atravessam a pé. Assim, entende-se que mesmo com a criação da APA o rio continua tendo seus aspectos naturais alterados.

\section{A participação do caranguejeiro na governança ambiental da APA/ARIE de Manguezais da Foz do Rio Mamanguape}

O manejo do recurso caranguejo-uçá realizada pelos caranguejeiros do estuário do Rio Mamanguape é feita isoladamente da governança das unidades de conservação. O desconhecimento por parte dos catadores de caranguejo acerca da existência da APA da Barra do Rio Mamanguape e ARIE de Manguezais da Foz do Rio Mamanguape demonstra claramente a total exclusão desses atores sociais do processo de gestão das UC.

Quando analisada a participação desses atores sociais no processo de criação da APA e da ARIE e sobre o que eles entendem por cada uma das UC's, verificou-se que $100 \%$ dos entrevistados desconhecem a existência das áreas protegidas na região e o seu significado, bem como desconhecem trabalhar no interior de uma UC, como pode ser observada nas falas abaixo.

"nunca oví falar de nenhum dos dois." (Risadinha) 
"eu conheço um pessoal que trabalha na APA, né ali no peixe-boi (projeto peixe-boi)?" (Bem-te-vi)

Os entrevistados afirmaram que não participaram e não foram informados da criação de ambas as unidades de conservação. No entanto, por meio da análise das falas verificou-se que $68 \%$ dos caranguejeiros conheceram a responsável pela criação da APA e que a mesma era uma figura presente nas comunidades.

Essa informação levanta alguns questionamentos: houve o compartilhamento de tais informações? O esquecimento ou desconhecimento desse fato importante está atrelado a um precário processo de sensibilização desses atores? Por ser um grupo marginalizado, eles foram excluídos do processo de gestão? A sociedade civil foi devidamente incluída no processo de criação da APA?

Os catadores de caranguejo mais velhos, que correspondem a $23 \%$ dos entrevistados (especialistas), lembram que a primeira gestora da APA realizava frequentemente visita às comunidades. Nessas circunstâncias, ela dialogava com os caranguejeiros, informando e estimulando a proteção do peixe boi e o cumprimento do período de andada do caranguejo uçá, embora o grupo não lembre de a mesma falar sobre a proteção especial do território através da APA e/ou da ARIE.

A centralização do poder nas mãos dos gestores públicos pode explicar os motivos do manejo dos recursos naturais ditos de uso comum não serem eficazes (Hardin, 1968). A descentralização da gestão dos recursos naturais tem como pressuposto a solidariedade e a participação social não tão somente na definição e monitoramento das ações do poder público, mas também, nos processos de tomadas de decisão (Scardua e Bursztyn 2003).

Através da análise das entrevistas, observou-se que 100\% dos entrevistados em algum momento tiveram algum contato com representantes do IBAMA ou ICMBio. Quando indagados sobre o que são estas instituições e quais as suas atribuições, os caranguejeiros entendem que se trata de um órgão que fiscaliza, apreende o caranguejo no período de andada, multa o caranguejeiro, e protege o peixe boi, sem distinção entre os dois órgãos.

Cabe esclarecer que para o caranguejeiro os servidores do ICMBIO são do IBAMA, uma vez que a criação da APA foi realizada pelo IBAMA, instituição responsável pelas unidades de conservação Federais na época. Após a criação do ICMBIO em 2007, houve a permuta de responsabilidade, mas essa mudança não é percebida pelos caranguejeiros, então eles entendem que o único órgão ambiental alocado no projeto peixe-boi e/ou que realizam ações na região foi e é o IBAMA.

Embora a visão dos caranguejeiros sobre o IBAMA/ICMBio seja de uma instituição autoritária, verificou-se que o grupo valoriza e considera necessário as ações deles na região, como será visto nas falas a seguir.

"eu sei bem poco do IBAMA, eu sei que ele faz as lei dele, né? Faz as coisa dele. Que as vezes tá prejudicando uma coisa e outra, tá queimando mangue, ele tem que dá em cima, que é o trabalho dele." (Bigodinho)

"Depois que o IBAMA entrô, foi muito bom pra gente. Que a coisa fechô mais um pôco, pra sorte da gente, embora que a gente as veze ache ruim." (Caboclinho)

Quando questionados sobre a frequência que o IBAMA/ICMBio vai nas comunidades, $88 \%$ dos entrevistados relata que quando a instituição estava alocada na comunidade de Barra de Mamanguape, 
no projeto peixe-boi, eles eram bem mais atuantes e presentes na comunidade. No entanto, existem discursos que perceberam que após anos afastados, representantes do órgão ambiental estiveram mais atuantes na comunidade no ano de 2017.

Quando os caranguejeiros foram questionados sobre o ICMBIO, verificou-se que $92 \%$ dos entrevistados nunca tinham ouvido falar do ICMBIO. Os $8 \%$ restantes relataram que tiveram o primeiro contato com representantes da instituição nas reuniões sobre o marco regulatório do Caranguejo-uçá que ocorreram em Tramataia e Taberaba em 2016-2017. Nas falas dos caranguejeiros que participaram desta reunião, ficou claro o quanto os catadores de caranguejo apreciaram o momento de integração e de geração de conhecimento, como pode ser observado na seguinte fala:

\footnotetext{
"de vez em quando ele vem fazê reunião com a gente. As vezes eles mandam me chamar, ai eu vou. Eu gosto de escutar. (o que eles estão falando aqui?) estão falando do rio, sobre o manguezal também, eles falam um bocado de coisa." (Andorinha-do-temporal)
}

Embora as reuniões tenham sido produzidas pelo ICMBIO, 67\% dos entrevistados atribuem a realização do evento ao IBAMA e/ou a Universidade Estadual da Paraíba (UEPB). O desconhecimento evidenciado, reflete mais uma vez o distanciamento ou a dificuldade de comunicação que existe entre ICMBIO e comunitários, assim como a ausência do catador de caranguejo na gestão das UC, fortalecendo a ideia de que o modelo de governança ambiental praticado nas áreas protegidas é de cunho hierárquico, centralizado e não compartilhado.

A consolidação de uma gestão democrática, integrada e compartilhada precisa ser urgentemente motivada nos gestores das unidades e nos catadores de caranguejo. Para isso, Sandstrom e Rova (2010) sugerem o fortalecimento de uma rede de governança adaptativa, que tem como preceitos básicos a gestão adaptativa e a rede social. Seu emprego contribuirá numa gestão de transparência, informativa, baseada nos princípios de cooperação e confiança entre os órgãos gestores e os caranguejeiros.

No tocante ao conselho gestor, $100 \%$ dos catadores afirmam nunca terem ouvido falar do colegiado, assim como nunca receberam qualquer notificação ou informação sobre as tomadas de decisão. Foi verificado também que os entrevistados desconhecem a participação de pessoas que representem os interesses do grupo em tal instância.

Os caranguejeiros (85\%) reconhecem que seria importante ter um representante deles nas reuniões do conselho gestor, para que as discussões relacionadas ao recurso sejam feitas baseadas na vivência deles de mangue. Os entrevistados também consideram importante a realização de reuniões para debaterem a questão do caranguejo. Segundo os entrevistados (74\%), os caranguejeiros se sentem desvalorizados, pois sempre que tem reunião nas comunidades é para falar dos viveiros de camarão e da agricultura e nunca do caranguejo.

\section{Considerações finais}

O estudo demostrou o afastamento que existe entre os catadores de caranguejo e a gestão da APA/ ARIE de Manguezais da Foz do Rio Mamanguape. Esse fato abre espaço para que seja questionado quais outros recursos têm seus usuários isolados do processo de gestão das UC, a exemplo das marisqueiras, dos catadores de ostra, aratu, guaiamum e siri. 
O uso do caranguejo uçá é regulamentado pela gestão local a partir de normativas emanadas de instancias superiores, no entanto, os usuários determinam suas próprias regras na captura do recurso. Tais regras são de cunho coletivo e individual, mas o que as tornam eficientes na proteção do caranguejo é a consciência ambiental do catador.

O exercício de uma gestão participativa e compartilhada não se expressa pela existência do conselho gestor, mas sim pela representação do grupo no colegiado. Assim, nesse estudo ficou evidente que os usuários não têm o conhecimento do funcionamento do conselho gestor, e que as demandas do grupo não fazem parte das prioridades dos conselheiros.

É urgente a criação de iniciativas que promovam a maior interação entre os gestores das UC e seu conselho gestor com as comunidades. Apesar de algumas iniciativas terem sido realizadas, como foi o caso das oficinas de atualização do marco regulatório do caranguejo uçá, é fundamental que seja estabelecido e fortalecido um canal de comunicação, contínuo, entre gestores e caranguejeiros, para que estes últimos participem da gestão das UC's e se sintam responsáveis pela proteção do mangue, do rio e do caranguejo.

Para fortalecer o exercício da gestão participativa e compartilhada, sugere-se a ampliação do campo de ações do conselho gestor das UC e suas assembleias sejam realizadas rotativamente nas comunidades. Essa estratégia estimulará a participação dos caranguejeiros e de outros pescadores tradicionais nas reuniões do conselho, provocando e estimulando o interesse dos grupos sociais na gestão da APA/ARIE. Para além do que foi dito, levar o conselho as comunidades é a forma eficiente de receber e repassar informações, assim como de conhecerem a realidade social, cultura, ambiental e econômica da região.

\section{Agradecimentos}

O presente trabalho foi realizado com apoio da Coordenação de Aperfeiçoamento de Pessoal de Nível Superior - Brasil (CAPES) - Código de Financiamento 001.

Participação dos autores: LMOS - Elaboração do projeto, coleta de dados, redação do artigo; GECM e JSM - Elaboração do projeto, revisão do artigo.

Aprovação ética e licenças: aprovado no Sistema de Autorização e Informação em Biodiversidade (SISBIO) através do código 63572337 e no Comitê de ética em pesquisa (CEP) da Universidade Federal da Paraíba (UFPB), pelo parecer nº 2.357.719.

Disponibilidade dos dados: Pesquisa resultado da dissertação de mestrado da primeira autora. Repositório da UFPB https://sig-arq.ufpb.br/arquivos/201814921333791099737a9f95fd87a21/Dissertao._Letyssia_Maynarth_de_O._Soares. pdf.

Fomento: A primeira autora foi bolsista de Mestrado da Capes.

Conflito de Interesses: Os autores declaram não haver conflito de interesses.

\section{Referências}

BCD. 2013. Mapeamento geoambiental e avaliação dos impactos ambientais como subsídios para o planejamento e gestão socioambiental do estuário do Rio Mamanguape/PB. Universidade Federal do Rio Grande do Norte, Natal, RN. Disponível em: https://repositorio.ufrn.br/jspui/handle/123456789/18530 Acesso em:15/09/2020 
Alves RRN, Nishida AK. 2003. Aspectos socioeconômicos e percepção ambiental dos catadores de caranguejouçá do estuário do Rio Mamanguape, Nordeste do Brasil. Interciencia, v.28, n. 1, p.36-43. DOI: htts://doi.org/0378$1844 / 03 / 01 / 036-08 \$ 3.00 / 0$

Alves RRN, Nishida AK; Hernández MIM. 2005. Environmental perception of gatherers of the crab 'caranguejo-uçá (Ucides cordatus, Decapoda, Brachyura) affecting their collection attitudes. Journal of Ethnobiology and Ethnomedicine, $\mathrm{n}^{\circ} 1$, art. 10. DOI: https://doi.org/10.1186/1746-4269-1-10

Brasil. 2000. Decreto-Lei no 9.985, de 18 de julho de 2000. Disponível em: < http://www.planalto.gov.br/ccivil_03/leis/ 19985.htm> Acesso em: 02/03/2020.

Brasil. 2003. Portaria no 034, de 24 de junho de 2003. Disponível em: < http://www.agricultura.gov.br/assuntos/aquiculturae-pesca/legislacao/defesos/portaria-ibama-no-34_06_2003.pdf/view> Acesso em: 02/03/2020.

Deslandes, SF, Neto OC, Gomes R. 2002. Pesquisa social: teoria, métodos e criatividade. Vozes. Petrópolis, RJ.

Driessen PJ, Dieperink C, Laerhoven FV, Runhaar HAC, Vermeulen WJV. 2012. Towards a conceptual framework for the study of shifts in modes environmental governance - Experiences from the Netherlands. Environmental Policy and Governance. v. 22, p. 143-160. DOI: https://doi.org/10.1002/eet.1580

Fenberg PB, Caselle JE, Claudet J, Clemence M, Gaines SD, García-Charton JA, Gonçalves EJ, Grorud-Colvert K, Guidetti P, Jenkins SR, Jones PJS, Sarah E, Lester SE, Mcallen R, Moland E, Planes S, Sørensenl TK. 2012. The science of european marine reserves: status, eficacy, and future needs. Marine Policy, v.36, p. 1012-1021. DOI: https://doi. org/10.1016/j.marpol.2012.02.021

Ferreira EM, Mourão JS, Rocha PD, Nascimento DM, Bezerra DMMSQ. 2009. Folk classification of the crab and swimming crab (Crustacea - Brachyura) of the Mamanguape river estuary, Northeastern - Brazil. Journal of Ethnobiology and Ethnomedicine. DOI: https:// doi:10.1186/1746-4269-5-22

Gerhardinger LC, Godoy EAS, Jones PJS. 2009. Local ecological knowledge areas in Brazil. Ocean \& Coastal Management, v.52, p.154-165. DOI: https://doi.org/10.1016/j.ocecoaman.2008.12.007

Hardin G. 1968. The Tragedy of the commons.

Jentoft S. 2015. Fisheries co-management research and the case-study method. Procedings of Workshop on Fisheries COmanagement. Disponível em: http://pubs.iclarm.net/Pubs/Way\%20Forward/10\%20Jentoft.pdf Acesso em: 02/03/2020.

Kalikoski DC, Seixas CS, Almudi T. 2009. Gestão compartilhada e comunitária da pesca no Brasil: avanços e desafios. Ambiente \&Sociedade, Campinas, v.XII,n.1,p.151-172,jan-jun. DOI:https://doi.org/10.1590/S1414-753X2009000100011

Klonowski VS, Paludo D. 1999. Barra de Mamanguape - PB: Estudo do impacto do uso de madeira de manguezal pela população extrativista e da possibilidade de reflorestamento e manejo dos recursos madeireiros. In: Série Cadernos da Reserva da Biosfera, Mata Atlântica, MAB, UNESCO, v. 16, p. 7-54. Disponível em: < http://www.rbma.org.br/rbma/pdf/ Caderno_16.pdf> Acesso em: 02/03/2020.

Linares Y, Colmenares L, Espinoza N, Cote M. 2009. El capital social: herramienta fundamental de las políticas públicas para el desarolo de las comunidades. Academia, Trijillo- Venezuella, v. VIII, n.15, jun. Disponível em: < http://www. saber.ula.ve/bitstream/handle/123456789/29819/articulo9.pdf? sequence=1\&isAllowed=y>, Acesso em: 02/03/2020

Machado IC, Nordi N, Henriques MB, Cardoso TA; Pereira OM. 2011. A integração da pesquisa ao conhecimento ecológico local no subsídio ao manejo: variações no estoque natural da ostra de mangue Crassostral ssp. Na Reserva Extrativista do Mandira. Cananéia-SP, Brasil. Ambiente \& Sociedade, Campinas, v. XIV, n.1, jan-jun. DOI: https://doi. org/10.1590/S1414-753X2011000100002

Micheli, F, Halpern BS, Cirioco S, Walbridge S, Ciriaco S, Ferretti F, Fraschetti S, Lewison R, Nykjaer L, Rosenberg AA. 2013. Cumulative human impacts on Mediterranean and Black Sea marine ecosystems: Assessing current pressures and opportunities. Plos one, v. 8, art.12, dec. DOI: https://doi.org/10.1371/journal.pone.0079889 
Nascimento DM, Ferreira E, Bezerra DMMSQ, Rocha PD, Alves RRN, Mourão JS. 2012. Capture techniques' use of Canranguejo-uçá crabs (Ucides cordatus) in Paraíba state (northeastern Brazil) and its social-environmental implications. Anais da Academia Brasileira de Ciência, v.88, n.4, p.1051-1064. DOI: https://doi.org/10.1590/S0001-37652012005000066

Nascimento DM, Alves AGC, Alves RRN, Barboza RRD, Diele K, Mourão JS. 2016. Na examination of techniques used to mangrove crabs, Ucides cordatus, in the Mamanguape River estuary, northeastern Brazil, with implication for management. Ocean \& Coastal Management, v.130, p.50-57. DOI: https://doi.org/10.1016/j.ocecoaman.2016.05.010

Nascimento DM, Mourão JS, Alves RRN. 2011. Substituição de técnicas de captura do caranguejo-uçá pela redinha, Sitientibus série Ciências Biológicas, v.11, n.2. DOI: https://doi.org/10.13102/scb68

Nascimento DM, Alves RRN, Barboza RRD, Schidt AJ, Diele K, Mourão JS. 2017. Commercial relationships between intermediaries and harvesters of the mangrove crab Ucides cordatus (Linnaeus, 1763) in the Mamanguape River estuary, Brazil, and their socio-ecological implications. Ecological Economics, v.131, p.44-51. DOI: DOI: https://doi.org/10.1016/j. ecolecon.2016.08.017

Ostrom E. 1990. Governing the Commons: The Evolution of institutions for collective action. Cambridge University Press. DOI: https://doi.org/10.2307/1243016

Rocha MSP, Mourão JS, Souto WMS, Barboza RRD, Alvez RRN. 2008. O uso dos recursos pesqueiros no estuário do Rio Mamanguape, estado da Paraíba, Brasil. Interciencia, v.33, n.12, p.903-909.

Ruddle K, Davis A. 2013. Local Ecological knowlwdgw (LEK) in interdisciplinar research and application: a critical review. Asian Fisheries Science, v.26, p.79-100.

Scardua FP, Bursztyn MAA. 2003. Descentralização da política ambiental no Brasil, Sociedade e Estado. Brasília, v.18, n.1/2, jan-dez. DOI: https://doi.org/10.1590/S0102-69922003000100014

Sandström A, Rova C. 2010. Adaptive Co-management Network: a comparative analysis of two fishery conservation areas in Sweden. Ecology and Society. DOI: http://doi.org/10.5751/ES-03531-150314

Sandström A, Bodin O, Crona B. 2015. Network governance form the top: the case oh ecosystem- based coastal end marine management. Marine Policy, v. 55, p. 57-63. DOI: https://doi.org/10.1016/j.marpol.2015.01.009

Silvestre LC, Farias DLS, Lourenço JDS, Barros SCA, Braga NMP. 2011. Diagnóstico dos impactos ambientais advindos de atividades antrópicas na APA da Barra do Rio Mamanguape. Enciclopédia Biosfera, Goiânia, v.7, n.12. Disponível em: < http://www.conhecer.org.br/enciclop/2011a/ambientais/diagnostico\%20dos\%20impactos.pdf> Acesso em: 02/03/2020.

Verson AM, Pedro JM. 2012. Memória como fonte de pesquisa em história e antropologia. Revista História Oral, v.15, n.2, p. 125-139. Disponível em: http://revista.historiaoral.org.br/index. php?journal=rho\&page=article\&op=view\&path\%5B\%5D=261\&path\%5B\%5D=293 Acesso em. 16 de maio de 2013. 